\title{
A New Safe and Effective Treatment for Chronic Refractory Tendinopathy
}

\author{
Bernard F Morrey* \\ Orthopedic Department, Mayo Clinic, USA
}

Submission: April 20, 2018; Published: May 25, 2018

*Corresponding author: Bernard F Morrey, Orthopedic Department, Mayo Clinic, 200 First St SW, Rochester MN 55905, USA; Tel: 507-284-8314; Fax: 507-284-8935; Email: morrey.bernard@mayo.edu

\begin{abstract}
Chronic refractory tendinopathy accounts for over 30 million office visit per year (2013). In spite of the considerable burden of disease this condition represents, there remains no consensus regarding treatment, or even what constitutes the chronic refractory state. Recent studies have clarified the definition of a chronic refractory process. More importantly an innovative new technology appears to offer potential solution at all anatomic sites of involvement for the majority of patients. In the last 6 years, the use of an ultrasonic device directed to the pathologic tissue under ultrasound image guidance has proven extremely safe and effective in over 70,000 treatments. As clinical studies emerge documented experience suggests this treatment is performed with the difficulty and safety of a cortisone injection but with the same benefit of surgery without the cost or morbidity.
\end{abstract}

Keywords: Chronic refractory tendinopathy; Elbow; Lateral epicondylitis; Ultrasound percutaneous tenotomy

\section{Introduction}

A recent study from the Mayo Clinic documented the here to fore unknown fact that symptoms of lateral epicondylitis persist for 6 months in about $20 \%$ of patients with this problem [1]. Further, in that cohort of the $20 \%$ of patients still experiencing continued pain, the mean time to resolution was an additional 24 months (Figure 1). These observations prompted the investigators to define chronic refractory epicondylitis as a condition persisting for more than 6 months despite appropriate treatment. Furthermore, a review of the ICD codes employed in 2013 in the United States included over 30 million with a diagnosis of chronic tendinopathy or fasciitis. While the burden of the disease is considerable, there is wide divergence in the literature regarding the optimum treatment of the chronic refractory condition.

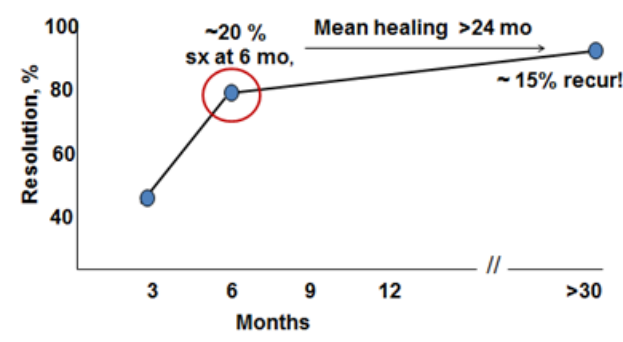

Figure 1: Demographic study of over 2000 cases studied for 10 years reveals most do improve or resolve by 8 months. However, failure to resolve by 6 months portends a poor prognosis with an mean time to resolution exceeding 24 additional months [1].
Since 2012 a novel approach to address this condition in the form of a percutaneous ultrasonic treatment was introduced. While ultrasonic or extracorporeal based treatment platforms have been employed in the past, wide spread acceptance has been limited due to the cost, discomfort unpredictable outcomes, complications and prolonged period of recovery. The phenomenal success of ultrasonic treatment for cataracts for over 20 years served as the stimulus to consider the same approach for another degenerative condition, tendinopathy [2]. The key features of this technology relate both to the device and to the technique

\section{Device}

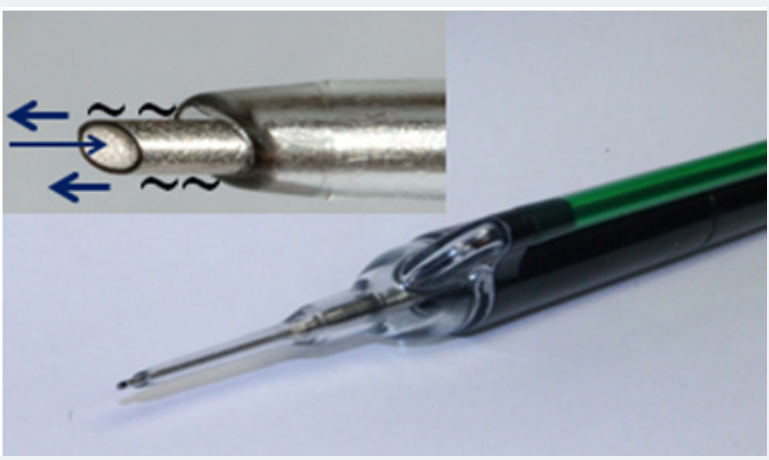

Figure 2: The device consists of a hollow ultrasonic probe to remove the diseased tissue (small arrow) with an outer sleeve used to cool the probe with saline (larger arrows) when in use. 


\section{Orthopedics and Rheumatology Open Access Journal (OROAJ)}

Ultrasonic energy is delivered through a hollow probe the size of an 18 gauge needle. The probe is hollow allowing suction to be applied which removes the tissue cut by the ultrasonic energy. A third essential element is continuous irrigation through a sleeve that surrounds the probe (Figure 2). The specific intensity of the energy has been observed to remove degenerative tissue but to have little effect on normal tendon (Figure 3).

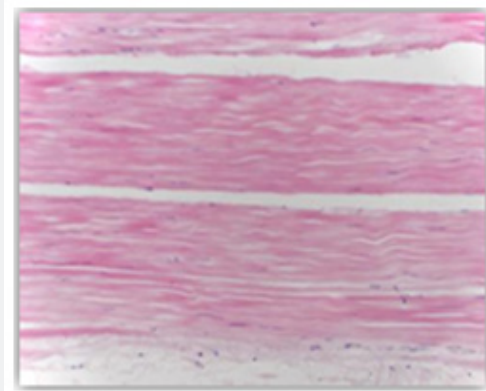

A

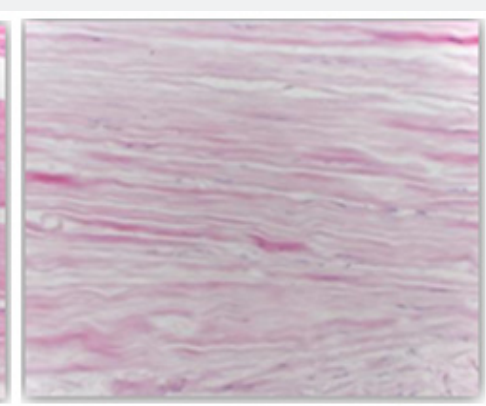

B

\section{Figure 3:}

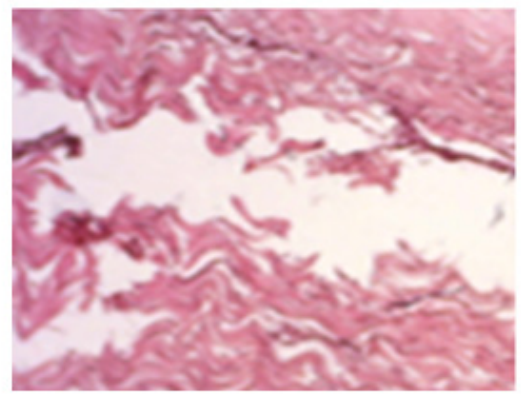

C

A. Histology of a normal tendon with organized tightly packed fibers.

B. After 7 seconds of continuous energy in a discrete point of application, little change in collagen morphology is noted, and there are no ruptured or fractured bundles.

C. Tendon experimentally degenerated with collagenase reveals a tract of removed tissue after treatment with the TX1 device.

Materials and Methods/Technique

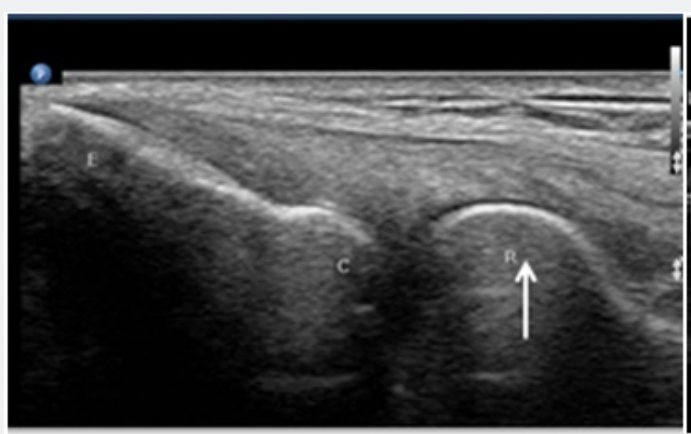

A

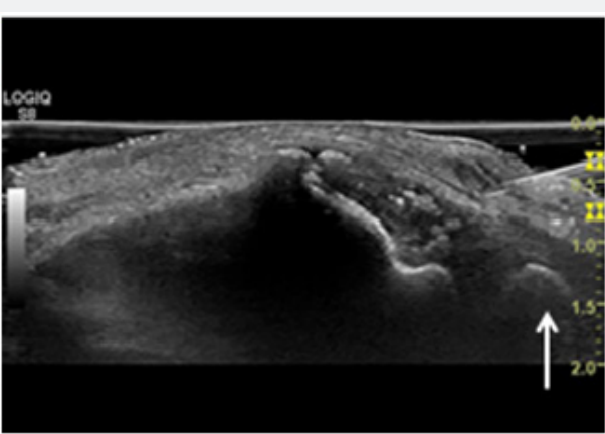

B

Figure 4:

A. An ultrasound image of a normal lateral epicondyle with a normal extensor tendon insertion. Note smooth osseous surface.

B. Classic hypoechoic appearance of tendinopathy. Involving the lateral epicondyle. Note irregularity of the osseous surface and blackened 'hypoechoic' tendon at site of attachment. White arrows identify the radial head.

The specific technique has been described in detail for the tennis elbow [3] and patellar tendinopathy [4]. The first step is to confirm the diagnosis is consistent with the clinical presentation. Next is the identification of the characteristic ultrasonic signal changes associated with tendinopathy [5]. Hypoechoic changes at the site of attachment of the involved tendon, or thickening $(>4 \mathrm{~mm})$ at the site of attachment of the plantar fascia at the medial tubercle of the calcaneus (Figure 4). Once the diagnosis 


\section{Orthopedics and Rheumatology Open Access Journal (OROAJ)}

is confirmed and the patient affirms desire to be treated, the involved area is sterilely prepared and isolated with sterile towels. The ultrasonic sensor is placed in a sterile sheaf and the area is anesthetized with a fast acting local anesthetic. An eleven blade makes a limited stab incision through skin and into the fascia, and the sterile, disposable hand piece is inserted to the site of pathology under ultrasonic guidance (Figures $5 a \& 5 b$ ).
Treatment with the ultrasonic energy, delivered by depressing a peddle varies from $60-90$ secs to 3-5 minutes for more difficult and extensive conditions. When a classic hypoechoic lesion is present, the diseased tendon undergoes an immediate change in signal appearing normoechoic. If this occurs the area has been adequately treated. The highlights of this procedure are shown in Table 1.

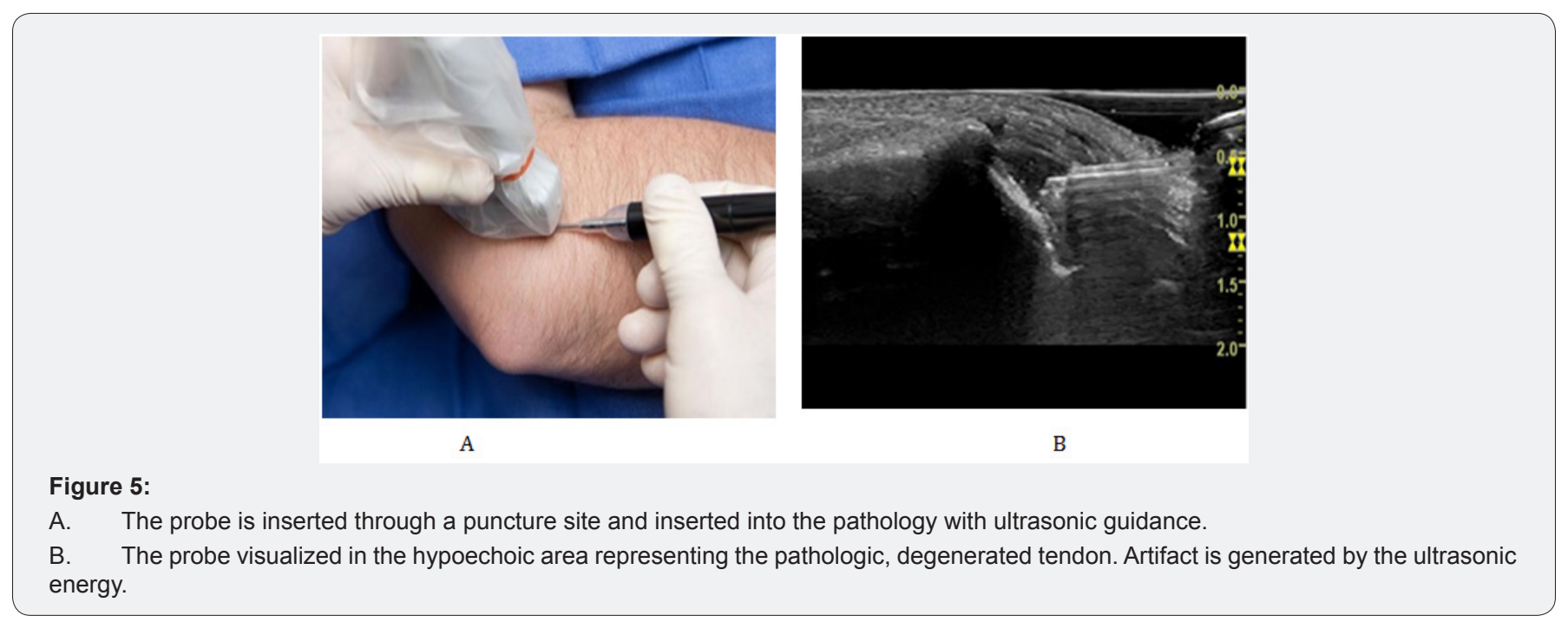

Table 1: Summary of the key features of the procedure.

\begin{tabular}{|c|}
\hline Technique \\
\hline Clinical exam; mark point of maximum tenderness \\
\hline Confirm lesion with US \\
\hline Prep - drape (steroid injection) \\
\hline Local anesthetic, go to bone \\
\hline Incise skin, and fascia \\
\hline Probe activated: back and forth motion \\
\hline Visual clues to completeness - less resistance to probe movement \\
$(\leftrightarrow 3-5 \mathrm{~mm})$ \\
\hline Treatment time 1-3mins \\
\hline
\end{tabular}

Aftercare although there is one randomized controlled study underway (Hall, personal communication) to date there are little data to direct the optimum post-procedure management. The most common approach is to recommend strict rest for 2-3 days; 3 weeks of limited, sedentary activity; 3-6 weeks of gradually resumption of normal activities; if symptoms are resolving, we allow activity as tolerated. We do not feel additional adjunctive treatment is necessary. However, for plantar fasciitis we do advise continued of a walking boot for a week or two if the patient has been using this before the procedure. The general post procedure guidelines are shown in Table 2.
Table 2: Outline of the important features of the post procedure period.

\begin{tabular}{|c|}
\hline Recovery (Under Investigation) \\
\hline Ice, Tylenol \\
\hline Rest - days \\
\hline Sedentary activity - to 3 weeks \\
\hline Resume routine activities - to 6 weeks \\
\hline Full activity - post 6 weeks (x2 longer for jumpers knee) \\
\hline No additional adjuncts \\
\hline Evaluate \\
\hline RTC, phone call: 1 -3 weeks; 1 -3 months; 6 months \\
\hline
\end{tabular}

\section{Results}

A growing body of literature has consistently reported a safe, well tolerated procedure with a high degree of success. An animal model study demonstrated the effect of treating the degenerated tendon is for a return of Type 1 and 3 collagens return to normal concentrations and ratios at three weeks [6] (Figure 6). This suggests the mechanism of cutting and removing the degenerated tendon has a stimulatory effect on the healing process, postulated to be facilitated by the absence of diseased tissue that has not resorbed. 


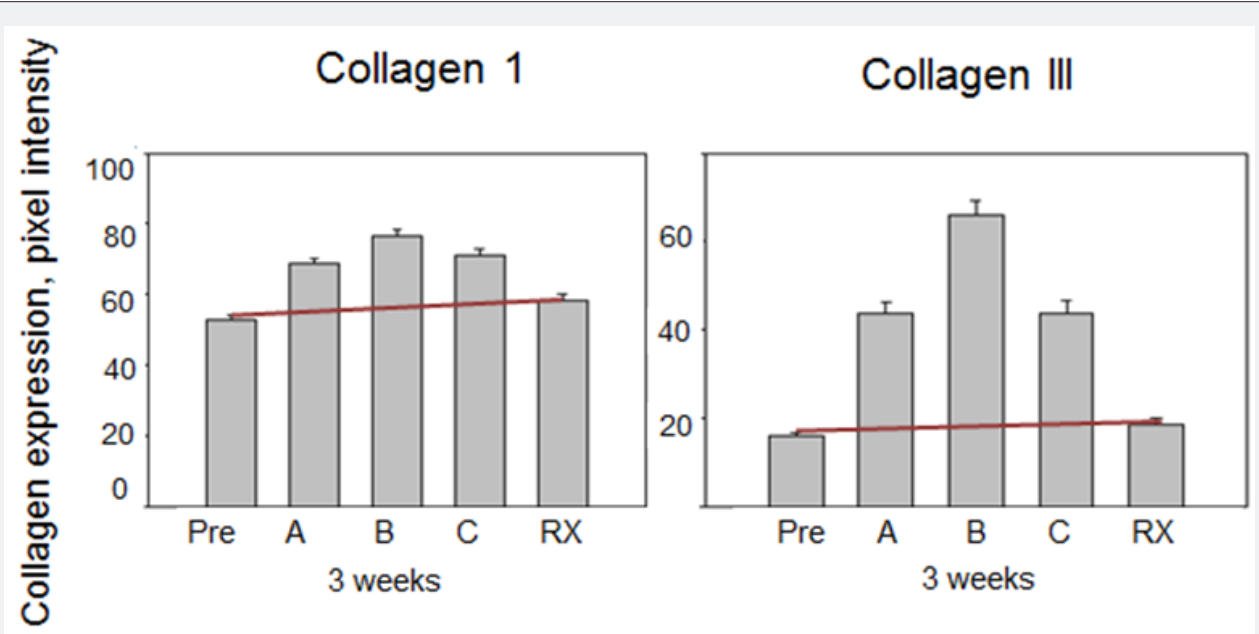

Figure 6: Laboratory data reveals the concentration of types 1 and 3 collagen return to normal in the rabbit experimental model three weeks after treatment [6].

Several technique reports have appeared and the optimum treatment characteristics are becoming better established $[3,4]$. The initial clinical report appearing in the peer reviewed literature was in 2013 by Koh et al. [7]. These investigators report a prospective study of 20 patients so treated and documented 19 of were pain free at one year. Importantly, they reassessed this cohort and reported all 20 to be pain free at 3 years [8]. Of particular note is all 20 also had serial ultrasonic examinations of the elbow and the progression to improve or even healed tendon was documented in each patient. This cohort of patients has also been carefully followed by US examinations at discrete intervals for the 3 year period. This assessment has revealed 14 of the 20 appeared completely normal when later examined by ultrasound imaging [8]. Similarly a prospective study from the Mayo clinic reported 12 lateral and 7 medial epicondylitis patients. At one year 17 or the 19(88\%) exhibited a satisfactory outcome [9]. Of interest, similar results have been documented at other sites of involvement: the knee (88\%); [4] Achilles insertion (88\%) [10]; plantar fasciitis (94\% - 100\%) [11] and hamstring insertionopathy at the pelvis [12]. With the introduction of the longer TX2 probe calcific tendonitis of the shoulder and gluteus tendinopathy are also being successfully treated. Of further interest is the documentation of successful salvage of failed open surgical intervention with this procedure $[11,13]$.

Finally, Patel has also employed the procedure for plantar fibroma and reported no recurrences in 10 patients after one year of treatment [14]. Hence the technique appears to effectively remove scar tissue without recurrence in the short term.

\section{Complications}

After over 70,000 procedures through the first part of 2018, there have been 14 reported complications requiring additional treatment (Table 3). The presence of these problems did not prevent the outcome from being favorable in 10 of the 14 .
Table 3: Complications requiring additional medical attention.

\begin{tabular}{|c|}
\hline Complications \\
\hline $13 / \sim 70,000$ required additional treatment \\
\hline Tendon rupture -3 (1 on Fluroquinolone) \\
\hline Nerve injury -1 permanent nerve injury \\
\hline Infection -2 ; both required I/D \\
\hline Probe breakage, retrieved -6 \\
\hline Skin burn $(?)-1$ \\
\hline
\end{tabular}

\section{Discussion}

Since introduction, there has been a rapid adoption and acceptance of the procedure [15-17]. Recent reviews on the topic of chronic tendinopathy have not only recognized the efficacy of this approach, but even declared it is the 'treatment of choice' for this condition [18]. As the clinical experience evolves we will find more failures [19]. But further experience will better define the sensitivity of the results to selection; technique; preoperative issues such as steroid injections, worker's compensation, and prior surgery; and post procedure treatment, including the need and value of adjunctive therapy, walking boot and the like.

\section{The Future}

As noted In September, 2015 a longer probe was introduced that allows for the treatment of calcific tendinopathy of the shoulder with the perception of markedly less recovery morbidity when compared to alternative treatment options. This device is also being widely used for gluteal tendinopathy with early clinical impression that this may be one of the most effective applications of the technology. Additional applications are being explored. Over 30 academic institutions are using this procedure in the United States and it is hoped additional prospective studies will be forth coming in the near future. 


\section{Author's Experience}

The author has treated over 475 patients since 2012. This experience parallels that of the literature with the elbow and the plantar fasciitis patients being most reliably improved (>90\%). However all treatment sites have had a similar overall success rate. There have been no complications requiring a physician's attention as yet in our practice. There have been 10 repeat procedures, 7 were overt failures while 3 represented extension of the initial pathology. The author has not performed an open or arthroscopic procedure for chronic tendinopathy since beginning to use this procedure.

\section{Conclusion}

The appropriate patient for definitive intervention is that patient with symptoms for six months or longer in spite of other treatment. This treatment option provides definitive treatment with the complexity of a steroid injection and with the effectiveness of surgery without the cost or morbidity. This degree of effectiveness coupled with the safety profile suggests this may well be the treatment platform of the future for this condition.

\section{Conflict of Interest}

Dr. Morrey is the medical director of Tenex Health.

\section{References}

1. Sanders TL, Maradit Kremers H, Bryan AJ, Ransom JE, Smith J, et al. (2015) The epidemiology and health care burden of tennis elbow: a population-based study. Am J Sports Med 43(5): 1066-1071.

2. Kelman CD (1994) The history and development of phacoemulsification. Int Ophthalmol Clin 34(2): 1-12.

3. Morrey BF (2013) Ultrasound percutaneous tenotomy for epicondylitis. Techniques in Shoulder and Elbow Surgery 14(2): 51-58.

4. Neal S Elattrache, Morrey B (2013) Percutaneous ultrasonic tenotomy as a treatment for chronic patellar tendinopathy-Jumper's Knee. Op Tech in Orthopaedics 23(2): 98-103.

5. Darryl E Barnes (2013) Ultrasonic energy in tendon treatment. Oper Tech Orthop 23: 78-83.

6. Kamineni S, Butterfield T, Sinai A (2015) Percutaneous ultrasonic debridement of tendonopathy-a pilot Achilles rabbit model. J Orth Surg Res 10: 70 .

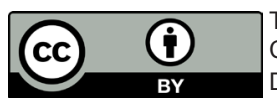

This work is licensed under Creative Commons Attribution 4.0 License DOI: 10.19080/OROAJ.2018.11.555825
7. Koh JS, Mohan PC, Howe TS, Lee BP, Chia SL (2013) Fasciotomy and surgical tenotomy for recalcitrant lateral elbow tendinopathy: early clinical experience with a novel device for minimally invasive percutaneous microresection. Am J Sports Med 41(3): 636-644.

8. Seng C, Mohan PC, Koh SB, Howe TS, Lim YG, et al. (2016) Ultrasonic percutaneous tenotomy for recalcitrant lateral elbow tendinopathy: Sustainability and sonographic progression at 3 years. Am J Sports Med 44(2): 504-510.

9. Barnes DE, Beckley JM, Smith J (2015) Percutaneous ultrasonic tenotomy for chronic elbow tendinosis: a prospective study. J Shoulder Elbow Surg 24(1): 67-73.

10. Ellis M, Johnson K, Freed L, Haddon T (2018) Fasciotomy and surgical tenotomy for chronic Achilles insertional tendinopathy: A retrospective study using ultrasound-guided percutaneous tenotomy approach. J Am Podiatr Med Assoc USA.

11. Patel MM (2015) A novel treatment for refractory plantar fasciitis. Am J Orthop 44: 107-110.

12. Ostrom E, Joseph A (2018) Percutaneous ultrasound tenotomy using the Tenex System on the adductor longus tendon: A pilot case series. MOJ Sports Med 2(1): 00035.

13. Hall MM, Woodroffe L (2017) Ultrasonic Percutaneous tenotomy for recalcitrant calcific triceps tendinosis in a competitive strongman: A case report. Curr Sports Med Rep 16(3): 150-152.

14. Patel M, Patel SM, Patel S, Daynes J (2015) A pilot study of a novel treatment method for refractory painful plantar fibromas. Austin J Orthopaed Rheumatol 2(2): 1014.

15. Sharma GS, Fung DA, Davis TT (2017) Percutaneous needle tenotomy and Tenex health Therapy in the Patient. In: Comprehensive pain management in the rehabilitation patient. Springer pp: 891-897.

16. Langer PR (2015) Two emerging technologies for Achilles tendinopathy and plantar fasciopathy. Clin Podiatric Med Surg 32(2): 183-193.

17. Erickson JL, Hall MM (2015) Evidence-based treatment of common extensor tendinopathy. Current Physical Med and Rehab Reports 3(1): 50-59.

18. Bhabra G, Wang A, Ebert JR, Edwards P, Zheng M (2016) Lateral elbow tendinopathy: Development of a pathophysiology-based treatment algorithm. Orthop J Sports Med 4(11): 2325967116670635.

19. Sanchez PJ, Grady JF, Saxena A (2017) Percutaneous Ultrasonic Tenotomy for Achilles Tendinopathy Is a Surgical Procedure With Similar Complications. J Foot Ankle Surg 56(5): 982-984.

\section{Your next submission with Juniper Publishers will reach you the below assets}

- Quality Editorial service

- Swift Peer Review

- Reprints availability

- E-prints Service

- Manuscript Podcast for convenient understanding

- Global attainment for your research

- Manuscript accessibility in different formats

( Pdf, E-pub, Full Text, Audio)

- Unceasing customer service

Track the below URL for one-step submission https://juniperpublishers.com/online-submission.php 